\title{
How do early career health sciences information professionals gain competencies? EC
}

\author{
Bethany A. Myers, MSLIS, AHIP; Bredny Rodriguez, MLS, AHIP
}

See end of article for authors' affiliations.

DOI: http://dx.doi.org/10.3163/1536-5050.104.3.006

\begin{abstract}
Objective: The purpose of this study was to describe early career health sciences information professionals' self-reported attainment of the Medical Library Association (MLA) Competencies for Lifelong Learning and Professional Success and to investigate the various methods by which participants developed these competencies.
\end{abstract}

Methods: A SurveyMonkey survey was designed to ascertain participants' demographic information and their competency attainment. "Early career" health information professionals were defined as those with less than five years of professional experience. Participants were asked to rate each of the seven competencies on a five-point Likert scale regarding their level of agreement with the statement, "I have demonstrated this competency." Participants who responded positively were then asked to indicate how they acquired the competency on a multiple-choice, multiple-answer list. Free-text fields were provided for general comments and for participants to elaborate on their answers. The survey was distributed through the MLA email discussion list and other related email discussion lists. Participation was anonymous.

Results: One hundred eighty-seven responses were received. Out of those 187 respondents, 95 completed the entire survey. The majority of early career health sciences information professionals agreed that they had attained all 7 competencies. Of the various methods used to develop competencies, the most selected method was formal library and information studies education. Participants were least likely to report attaining competencies via mentoring, volunteering, or internships. Participants reported the highest level of confidence in having attained the "Health Sciences Information Services" competency, and the lowest level of confidence in having attained the "Research, Analysis, and Interpretation" competency.

Conclusions: These results contribute to the ongoing discussions regarding proposed changes to the MLA competencies. The results may also inform the development of educational and professional development opportunities for prospective or early career health information professionals.

Keywords: Medical Subject Headings: "Librarians"[Mesh], "Library Science"[Mesh], "Libraries"[Mesh], "Professional Competence/Standards"[Mesh], "Staff Development"[Mesh]

Librarians have spent decades discussing the role of formal library education in preparing entry-level librarians. Some contend that library and information studies (LIS) education is failing to provide practical, competitive skills for a professional career, while others hold that LIS education provides a necessary theoretical foundation in the academic discipline of

Supplemental Appendix A and Appendix B are available with the online version of this journal. information science that might not be emphasized in a vocationally oriented program [1-3]. Both perspectives conclude that library school is not a standalone, comprehensive method of preparing librarians for the realities of the library and information services work environment. This has resulted in a gap between the requirements of entrylevel positions and the abilities of new graduates. If these new graduates did not gain entry-level competencies via their degree programs, they must 
bridge this gap in other ways to develop the skills they need to succeed in their jobs.

This gap becomes especially significant in the health sciences environment. New health sciences information professionals are expected to support a wide variety of disciplines and specialties in biomedical education, research, and health care delivery, in increasingly complex academic and clinical contexts. Many health sciences librarians (including the authors) enter the field without a health sciences background. Thus, gaps in library knowledge are compounded by gaps in health sciences subject knowledge, which may affect early career information professionals' preparedness and confidence in their abilities to perform their new job duties.

There is no uniform set of skills needed to succeed as a new health sciences information professional, because position requirements can vary wildly among different roles at different types of institutions. However, the Medical Library Association (MLA) has identified some common areas of knowledge for health sciences librarians in their seven Competencies for Lifelong Learning and Professional Success [4]:

n "Health Sciences and Health Care Environment and Information Policies"

- "Leadership and Management Theory and Techniques"

- "Health Sciences Information Services"

- "Health Sciences Information Resource Management"

- "Information Systems and Technology"

- "Curricular Design and Instruction"

- "Research, Analysis, and Interpretation"

While entry-level librarians are not expected to have mastered all seven competencies and mastery is considered a lifelong, ongoing process, the competencies nevertheless represent foundational areas of knowledge that are flexible enough to apply to many health sciences information positions.

There is little recent research published on the ways in which entry-level health sciences information professionals acquire professional competencies. This study sought to describe early career health sciences professionals' competency development by assessing participants' sense of preparedness for their jobs and their perspectives on formal and informal education and training through the framework of the seven competencies.

\section{METHOD}

The survey comprised a total of fifty questions. The first thirteen questions were demographic in nature. Participants were asked about degree attainment, employment status, type of employer, and length of employment. To define an "early career" participant demographic, the authors used the same criteria set by the Academy of Health Information Professionals (AHIP) for provisional status. Academy provisional status is designed for health information professionals with less than five years of professional experience [5]. Only candidates who reported less than five years of professional experience were advanced to the competencies section of the survey. Participants who did not meet the predetermined demographic criteria were directed to the end of the survey and thanked for their participation.

The authors used MLA's published Competencies for Lifelong Learning and Professional Success [4] to investigate the self-perceived career preparedness of participants who advanced to the competencies section of the survey. The competencies portion of the survey was presented one competency at a time, with a description and examples for each of the seven competencies. For each competency, the survey asked the participants to rate on a five-point Likert scale whether or not they believed that they had attained this competency. Participants who selected neutral, disagree, strongly disagree, or not applicable were asked to elaborate and explain their selections in a free-text field. Participants who responded positively to having acquired a competency were then asked to indicate how they acquired it, using a multiple-choice, multiple-answer list:

- LIS education

- Other formal education (e.g., degree or certificate program)

- Work experience prior to LIS career

- Internship, fellowship, residency, or other

preprofessional formal training program

- Volunteering or other preprofessional informal

training

- Mentoring relationship

- Peer or colleague relationship

- Employer-provided training

- MLA or other organization, continuing education (CE) courses, etc.

- Other (please specify)

Definitions were not provided for these methods of attainment. 
The University of California, Los Angeles (UCLA), Office of the Human Research Protection Program Institutional Review Board granted the authors exempt certification for this study. The survey instrument was created using SurveyMonkey. The survey was distributed to the MEDLIB-L email discussion list, which is sponsored by MLA (Appendix A, online only). MEDLIB-L is open to the public and includes subscribers who are not MLA members as well as MLA members who have opted to subscribe. Additionally, the survey was distributed to the thirteen officially recognized MLA chapters through their respective email discussion lists. The survey was also promoted on the authors' personal social media accounts. The survey was anonymous, and participants' Internet protocol (IP) addresses were not recorded. Data were collected during March 2015. Data outputs indicated the number of participants who answered or skipped any particular question. Descriptive statistics, frequency, and contingency tables for categorical variables were generated.

\section{RESULTS}

Of the 187 individuals who responded to the survey, 128 progressed to the competencies section (59 dropped out). The competencies section of the survey asked participants to rate on a 5-point Likert scale whether or not they believed that they have attained each of the 7 competencies. One hundred fourteen $(89.1 \%)$ of the 128 participants completed all 7 of the Likert scales, 1 for each competency. The majority of participants responded positively to the statement, "I have demonstrated this competency" for all 7 competencies. Few negative responses were received. Of the 128 participants who advanced to the competencies section, $95(74.2 \%)$ completed the method of attainment follow-up questions for all 7 competencies.

Full descriptions of each competency can be found in the survey instrument (Appendix B, online only). Table 1 displays results for the competencies' methods of attainment. Results for each of the seven competencies are presented below.

\section{"Health Sciences and Health Care Environment and Information Policies"}

Understand the health sciences and health care environment and the policies, issues, and trends that impact that environment.
The methods of attaining this competency were more widely distributed across attainment methods, compared to the other competencies. More than half of respondents indicated attaining the "Health Sciences Environment" competency through MLA, other professional organizations, or CE courses. This was the only competency wherein LIS education was not the top cited method of attainment: less than one in three respondents selected this method of competency attainment. This gap was summarized by one participant:

"MLA does good work. I just wish I had more of a solid grounding in LIS in school. I feel like I missed a class or something, and it's hell to 'catch up'. I do the best I can, but I doubt I'm alone in this."

\section{"Leadership and Management Theory and Techniques"}

Know and understand the application of leadership, finance, communication, and management theory and techniques.

LIS education was the most selected method of attainment for this competency (64.5\%). Peer or colleague relationships was the second most selected method of attainment. Mentoring was more frequently chosen as a method of attainment for this competency $(30.8 \%)$ in comparison to its selection in the other 6 competencies. In free-text responses, some participants noted that they acquired leadership and administration experience from previous careers. The survey's demographic section indicated that 56 participants had previous professional experience before becoming an information professional. Of those 56 with any amount of previous professional experience, 35 $(62.5 \%)$ had more than 5 years of previous professional experience.

\section{"Health Sciences Information Services"}

Understand the principles and practices related to providing information services to meet users' needs.

LIS education and MLA or CE were the most cited methods of attainment for this competency. The Likert-scale results showed that participants felt the most confident that they had acquired this competency, with $65.5 \%$ answering "strongly agree." This competency also had the fewest number of free- 


\begin{tabular}{|c|c|c|c|c|c|c|c|}
\hline & $\begin{array}{l}\text { "Health } \\
\text { Sciences and } \\
\text { Health Care } \\
\text { Environment" }\end{array}$ & $\begin{array}{l}\text { "Leadership and } \\
\text { Management } \\
\text { Theory and } \\
\text { Techniques" }\end{array}$ & $\begin{array}{l}\text { "Health } \\
\text { Sciences } \\
\text { Information } \\
\text { Services" }\end{array}$ & $\begin{array}{c}\text { "Health } \\
\text { Sciences } \\
\text { Resource } \\
\text { Management" }\end{array}$ & $\begin{array}{l}\text { "Information } \\
\text { Systems and } \\
\text { Technology" }\end{array}$ & $\begin{array}{l}\text { "Curricular } \\
\text { Design and } \\
\text { Instruction" }\end{array}$ & $\begin{array}{l}\text { "Research, } \\
\text { Analysis, and } \\
\text { Interpretation" }\end{array}$ \\
\hline Number of respondents & 106 & 107 & 112 & 100 & 100 & 101 & 95 \\
\hline \multirow{2}{*}{\multicolumn{8}{|c|}{ Library and information studies }} \\
\hline & $32.1 \%$ & $64.5 \%$ & $77.7 \%$ & $80.0 \%$ & $67.0 \%$ & $70.3 \%$ & $64.2 \%$ \\
\hline Other formal education & $21.7 \%$ & $27.1 \%$ & $17.0 \%$ & $10.0 \%$ & $21.0 \%$ & $30.7 \%$ & $45.3 \%$ \\
\hline \multicolumn{8}{|l|}{ Work experience prior to LIS } \\
\hline career & $\begin{array}{l}37.7 \% \\
15.1 \%\end{array}$ & $44.9 \%$ & $36.6 \%$ & $27.0 \%$ & $40.0 \%$ & $39.6 \%$ & $26.3 \%$ \\
\hline Internships or formal training & $15.1 \%$ & $20.6 \%$ & $29.5 \%$ & $23.0 \%$ & $17.0 \%$ & $21.8 \%$ & $12.6 \%$ \\
\hline Volunteering or informal training & $11.3 \%$ & $15.9 \%$ & $17.0 \%$ & $6.0 \%$ & $6.0 \%$ & $9.9 \%$ & $5.3 \%$ \\
\hline Mentoring & $22.6 \%$ & $30.8 \%$ & $25.9 \%$ & $16.0 \%$ & $15.0 \%$ & $17.8 \%$ & $14.7 \%$ \\
\hline Peer or colleague & $41.5 \%$ & $56.1 \%$ & $53.6 \%$ & $53.0 \%$ & $40.0 \%$ & $52.5 \%$ & $32.6 \%$ \\
\hline \multirow{2}{*}{$\begin{array}{l}\text { Employer provided training } \\
\text { MLA or other organization, } \\
\text { continuing education, etc. }\end{array}$} & $36.8 \%$ & $50.5 \%$ & $43.8 \%$ & $41.0 \%$ & $43.0 \%$ & $36.6 \%$ & $30.5 \%$ \\
\hline & $52.8 \%$ & $38.3 \%$ & $60.7 \%$ & & $40.0 \%$ & $55.4 \%$ & $43.2 \%$ \\
\hline
\end{tabular}

Table 1

Methods of attaining competencies

text responses to the Likert scale. The 2 negative responses indicated that the participants felt they were still too new to their positions to have acquired this competency.

\section{"Health Sciences Information Resource Management"}

Have the ability to manage health information resources in a broad range of formats.

This competency had the largest gap between the most (LIS education, chosen by $80.0 \%$ ) and least cited methods (volunteering, chosen by $6.0 \%$ ) of attainment. Although LIS education was the most cited method of attainment for 6 of the 7 competencies, LIS education had its strongest performance in this competency, with 4 out of 5 participants selecting this method. For participants responding negatively to having attained this competency, the majority of the free-text responses cited the functional nature of their organizational structure as a barrier to acquiring this competency. One respondent summarized:

"Most of these aren't involved in my day to day work duties, I don't feel the need to understand all of them at a deep level, just well enough to suit my own needs."

\section{"Information Systems and Technology"}

Understand and use technology and systems to manage all forms of information.
Employer-provided training had its best performance in the survey in this competency, being the second most cited method of attainment. Some respondents agreed that while they had a basic understanding of these systems, their current positions did not have many opportunities to expand their information technology skills. One respondent offered:

"I know the basics but since I do not have the opportunity to do this sort of work often in my position I do not get the experience to say I have achieved this competency. Maybe I will have a different answer a few years down the line."

\section{"Curricular Design and Instruction"}

Understand curricular design and instruction and have the ability to teach ways to access, organize, and use information.

The cited methods of attainment for this competency generally followed the trends of the other six competencies. In free-text responses, participants indicated that while they felt that they had attained the competency through CE and LIS education, they lacked formal pedagogical education. Curricular design as a skill was of special interest, with one participant commenting:

"I've taken one or two CE classes on the topic to satisfy the requirement for AHIP designation, but don't really feel this is a strong area of expertise. I understand the concepts and apply them, but am not confident in teaching." 


\section{Research, Analysis, and Interpretation}

Understand scientific research methods and have the ability to critically examine and filter research literature from many related disciplines.

This competency had the lowest weighted average on the attainment Likert scale and received the highest number of negative responses of all the competencies. In free-text responses, participants with academic training in the health or biomedical sciences suggested that this background was valuable in attaining this competency:

"I find that my degree in life sciences (biology) helped me a lot in gaining a lot of competencies required in this profession."

\section{DISCUSSION}

Survey results indicate that early career health information professionals largely rely on their LIS educational experience and MLA or CE opportunities to attain professional competencies. Among the methods of attainment, LIS education was selected most frequently. MLA or CE was in the top four methods of attainment for every area except "Leadership and Management Theory and Technique." Respondents used the free-text fields to describe the challenges that they faced in acquiring each of the seven competencies. Competency development takes time and experience, and is an ongoing process throughout an entire career [4], yet librarianship requires a large and diverse skill set from the first day on the job.

The survey results represented a variety in perceptions of what constitutes "on the job" training. The survey did not include "on the job" as a specific category, with the intention that "on the job" would consist of a specific learning vehicle, such as employer-directed training (included in the multiple choice options as "employer-provided training") or self-directed training facilitated by one of the other multiple choice options. However, for all seven competencies, participants frequently selected "other" as a method of attainment and used the freetext field to indicate that they developed the competency "on the job." Other free-text responses elaborated on participants' self-directed learning: they learned "on the job" via massive open online classes (MOOCs), email discussion lists, personal reading of library journals or blogs, and informational sessions or webinars provided by vendors and others.

Librarians have had a long tradition of learning on the job. Sixty-seven years ago, Janet Doe stated, "A description of the development of education for medical librarianship can be brief indeed. Such education has been almost wholly the old apprenticeship method of learning on the job" [6]. Later research also found that on-the-job training was emphasized by new health sciences librarians as an exceptionally valuable experience, prompting the author to suggest, "Perhaps MLA could help make such training available to a greater number by encouraging libraries to design and institute worthwhile internships" [7]. A 2011 study describes new hospital librarians in the United Kingdom developing skills on the job through a legitimate peripheral participation model. This is a "learn as you go" approach to training that paces new librarians through increasingly more difficult tasks, developing their independence as they learn alongside more experienced colleagues [8].

\section{Limitations}

The survey was intended to reach as many US early career health information professionals as possible, including those who might not be members of MLA or the Academy of Health Information Professionals. However, the use of MEDLIB-L (despite public availability) and local MLA chapter email discussion lists to distribute the survey might have biased responses toward MLA members. The authors did not consider demographic data in this analysis apart from participants' years of professional experience. Individual responses were not analyzed for associations between demographic characteristics and methods of attainment. The methods of attainment were presented equally, with no option to rank or weight each selection. The relative merit, impact, preference, or usefulness of each method was not assessed. The survey did not provide specific definitions for the methods of attainment. Certain methods, such as LIS education or peer relationships, might have a broad range of subjective definitions.

\section{CONCLUSION}

As health sciences librarians deal with new and evolving issues regarding scholarly communications, emerging technologies, data management, and other areas of importance to their communities, they must 
be provided structured opportunities for development. These survey data may inform the creation of such professional development opportunities. These data may also provide context for updates to the MLA competencies by illuminating early career health information professionals' self-reported strengths and weaknesses. Future research should be conducted on the ways in which health information professionals gain and apply a diverse and expanding set of knowledge, skills, and abilities to their jobs. In-depth studies are needed to identify health information professionals' specific information-seeking behaviors and learning preferences to facilitate their professional success

\section{REFERENCES}

1. Holt RE. Shibboleth: a next-generation view of the MLS. Libr Rev. 2005;54(9):519-23. DOI: http://www.dx. doi.org/10.1108/00242530510629533.

2. Gorman M. Whither library education? New Libr World. 2004;105(9/10):376-80. DOI: http://www.dx.doi. org/10.1108/03074800410557330.

3. Audunson R. Library and information science education - discipline profession, vocation? J Educ Libr Inf Sci. 2007;48(2):94-107.

4. Medical Library Association. Competencies for professional success: the educational policy statement of the Medical Library Association. Chicago, IL: The Association; 2007.
5. Medical Library Association. Getting started...academy requirements for every level [Internet]. Chicago, IL: The Association; 2015 [cited 16 Nov 2015]. <http://www. mlanet.org $/ \mathrm{p} / \mathrm{cm} / \mathrm{ld} / \mathrm{fid}=323>$.

6. Doe J. The development of education for medical librarianship. Bull Med Libr Assoc. 1949 Jul;37(3):213-20. 7. Blair JC, Jr. Informational needs of student and beginning health sciences librarians. Bull Med Libr Assoc. 1979 Apr;67(2):251-4.

8. Clarke S, Thomas Z. Health librarians: developing professional competence through a 'legitimate peripheral participation' model. Health Inf Libr J. 2011 Dec;28(4): 326-30. DOI: http://www.dx.doi.org/10.1111/j.1471-1842. 2010.00959.x.

\section{AUTHORS' AFFILIATIONS}

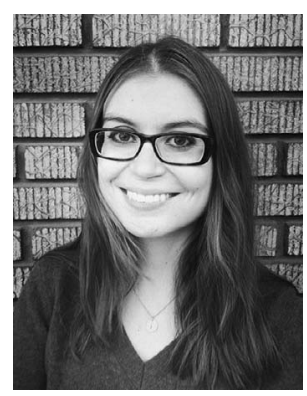

Bethany A. Myers, MSLIS, AHIP, bethanymyers@ library.ucla.edu, Research Informationist; Bredny Rodriguez, MLS, AHIP, brednyr@ library.ucla.edu, Health and Life Sciences Informationist; Louise M. Darling Biomedical Library, University of California, Los Angeles, 12-077 Center for Health Sciences, Box 951798, Los Angeles, CA 90095

Received November 2015; accepted February 2016 